\title{
INFLUENCE OF SAND BASE PREPARATION ON PROPERTIES OF CHROMITE MOULDING SANDS WITH SODIUM SILICATE HARDENED WITH SELECTED METHODS
}

\begin{abstract}
The paper presents a research on the relation between thermal preparation of chromite sand base of moulding sands containing sodium silicate, hardened with selected physical and chemical methods, and structure of the created bonding bridges. Test specimens were prepared of chromite sand - fresh or baked at $950^{\circ} \mathrm{C}$ for 10 or 24 hours - mixed with 0.5 wt. $\%$ of the selected non-modified inorganic binder and, after forming, were hardened with $\mathrm{CO}_{2}$ or liquid esters, dried traditionally or heated with microwaves at $2.45 \mathrm{GHz}$. It was shown on the grounds of SEM observations that the time of baking the base sand and the hardening method significantly affect structure of the bonding bridges and are correlated with mechanical properties of the moulding sands. It was found that hardening chromite-based moulding mixtures with physical methods is much more favourable than hardening with chemical methods, guaranteeing also more than ten times higher mechanical properties.

Keywords: foundry engineering, chromite sand, hydrated sodium silicate, strength properties, microwave hardening
\end{abstract}

\section{Introduction}

The group of raw materials used in masses in manufacture of castings includes high-silica, olivine, chromite, zircon, magnesite, corundum and other sands. With regard to generally easy availability and low purchase cost, the material most often used for moulding mixture bases is high-silica moulding sand. However, because of more favourable physico-chemical properties, foundries are introducing more expensive olivine and chromite sands. With regard to its fire resistance (melting point between 1700 and $\left.1900^{\circ} \mathrm{C}\right)[1,2]$ and better dimensional stability thanks to low linear expansion, chromite sand is particularly interesting. Linear expansion of chromite at $1400^{\circ} \mathrm{C}$ is only ca. $1.4 \%$ [3]. However, chromite sand obtained from chromium ore is one of the most expensive sands because of availability of raw material and its high density ranging from 4.5 to $4.8 \mathrm{~g} / \mathrm{cm}^{3}$. In comparison to the most popular moulding sand base, i.e. high-silica sand, bulk density of chromite sand is two times higher.

Its favourable properties, like chemical and thermal resistance, are contributed to the spinel phase with the general formula $\mathrm{A}^{2+} \mathrm{B}_{2}{ }^{3+} \mathrm{O}_{4}$ [1-3]. Its main components are $\mathrm{Cr}_{2} \mathrm{O}_{3}$ and $\mathrm{FeO}$ [3]. Moreover, depending on their place of origin [4], chromium ores contain magnesium oxide $(\mathrm{MgO})$, aluminium oxide $\left(\mathrm{Al}_{2} \mathrm{O}_{3}\right)$, iron oxides $\left(\mathrm{Fe}_{2} \mathrm{O}_{3}, \mathrm{Fe}_{3} \mathrm{O}_{4}\right)$ and manganese oxide $(\mathrm{MnO})$, as well as admixtures of titanium, vanadium, nickel and cobalt. In individual minerals from the group of chromium spinels, concentration of $\mathrm{Cr}_{2} \mathrm{O}_{3}$ ranges between 18 and $62 \%$ [4] or between 31 and $58 \%[2,3]$, and concentration of $\mathrm{FeO}$ ranges between
13 and $21.6 \%$. Concentration of $\mathrm{Cr}_{2} \mathrm{O}_{3}$ in chromite sand used in foundry practice should be at least $36 \%[2,3,5]$.

It can be inferred from practice and from literature data that in chromite-based moulding mixtures used are only the binders with high bonding power, i.e. synthetic resins [6-7] and hydrated sodium silicate (water-glass) [8-10] in spite of its silica content but with ecologically advantageous of inorganic structure [11]. In the case of waste quartz-chromite moulding sands, useful information is available [12-14] on the ways of reducing $\mathrm{SiO}_{2}$ content with respect to its environmental noxiousness and reduced fire resistance of reclaimed chromite base. This is caused by the created fusible eutectic mixture containing $\mathrm{FeO}$ and $\mathrm{SiO}_{2}$ $[2,13]$, resulting in sintered places. It can be often found in published papers that properties of a moulding sand are improved by baking fresh chromite sand at $950^{\circ} \mathrm{C}$ for 10 [1-2] or 24 hours, as practiced is some foundries. However, it is difficult to find more detailed information on chromite sand as the basic component of moulding sands and on the phenomena occurring during its application as fire-resistant base of moulding mixtures.

\section{Objective of the research}

Results of own research works [15-17] have inspired us to continue evaluation of chromite sand as prospective base of moulding sands that could be used as eco-friendly and economical moulding sands, possibly also as circulating foundry materials.

\footnotetext{
WROCŁAW UNIVERSITY OF TECHNOLOGY, WYBRZEŻE WYSPIAŃSKIEGO 25, 50-370 WROCŁAW, POLAND

Corresponding author: mateusz.stachowicz@pwr.edu.pl
} 
Chromite sand (Table 1) was produced by Magnesite Works "Ropczyce" S.A. Fresh chromite sand $(0 \mathrm{~h})$ was then baked at $950^{\circ} \mathrm{C}$ in a silit furnace for $10(10 \mathrm{~h})$ and 24 hours $(24 \mathrm{~h})$ and cooled-down to ambient temperature. Baking of the sand base was aimed at explaining the phenomena cyclically occurring in chromite sand during pouring the moulds and solidification of the castings inside. The examinations can also confirm the reportedly $[1,2]$ favourable result of baking at $950^{\circ} \mathrm{C}$ for innovative ways of preparing moulds and cores, like microwave heating [15].

The binder was non-modified commercial hydrated sodium silicate R145 made by Chemical Plant "Rudniki" S.A., with properties given in (Table 1).

TABLE 1

Basic parameters of moulding materials used in the research

\begin{tabular}{|c|c|c|c|c|}
\hline \multicolumn{5}{|c|}{ Chromite sand base: } \\
\hline \multicolumn{3}{|c|}{ Main fraction: } & \multicolumn{2}{|c|}{$0.20 / 0.315 / 0.4$} \\
\hline \multicolumn{3}{|c|}{ FeO content [\%]: } & \multicolumn{2}{|l|}{29.0} \\
\hline \multicolumn{3}{|c|}{$\mathrm{Cr}_{2} \mathrm{O}_{3}$ content $[\%]:$} & \multicolumn{2}{|l|}{46.5} \\
\hline \multicolumn{3}{|c|}{$\mathrm{MgO}$ content $[\%]:$} & \multicolumn{2}{|l|}{9.8} \\
\hline \multicolumn{3}{|c|}{$\mathrm{SiO}_{2}$ content $[\%]:$} & \multicolumn{2}{|l|}{0.8} \\
\hline \multicolumn{5}{|c|}{ Sodium silicate grade R145: } \\
\hline $\begin{array}{c}\text { Molar } \\
\text { module } \\
\mathrm{SiO}_{2} / \mathrm{Na}_{2} \mathrm{O} \\
\end{array}$ & $\begin{array}{c}\text { Oxide content } \\
\left(\mathrm{SiO}_{2}+\mathrm{Na}_{2} \mathrm{O}\right) \\
{[\%]} \\
\end{array}$ & $\begin{array}{l}\text { Density } \\
\left(20{ }^{\circ} \mathrm{C}\right) \text {, } \\
{\left[\mathrm{g} / \mathrm{cm}^{3}\right]} \\
\end{array}$ & $\begin{array}{c}\mathrm{Fe}_{2} \mathbf{O}_{3}, \\
\max .[\%]\end{array}$ & $\begin{array}{l}\text { Dynamic } \\
\text { viscosity, } \\
\text { min. (P) }\end{array}$ \\
\hline 2.5 & 41.5 & 1.47 & 0.01 & 1 \\
\hline
\end{tabular}

\section{Effect of baking on chromite base grains}

In order to observe the changes caused by baking chromite sand, a series of photographs was taken by means of a scanning microscope Hitachi TM-3000 equipped with an EDS analyser. Effects of temperature on surfaces of chromite grains are shown in the images of polished sections, see (Fig. 1). It can be seen in the photographs that a superficial rough layer grows with exten-
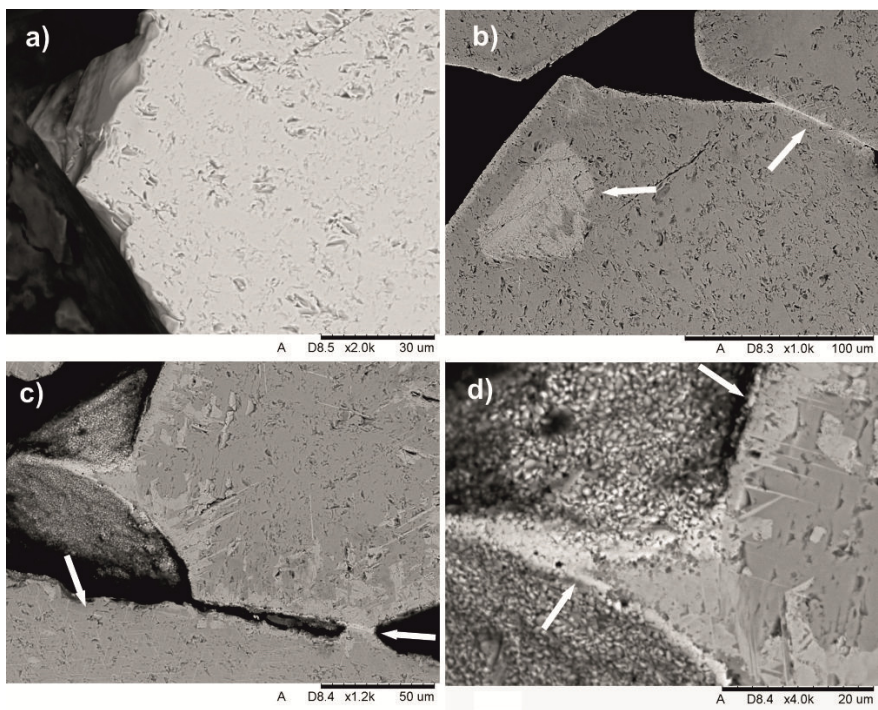

Fig. 1. View of sections: a) fresh chromite sand $-0 \mathrm{~h}, \mathrm{~b}$ ) after $10 \mathrm{~h}, \mathrm{c})$ and d) after $24 \mathrm{~h}$ of baking at $950^{\circ} \mathrm{C}$ sion of baking time from 10 to $24 \mathrm{~h}$. The about 1 to $2 \mu \mathrm{m}$ thick layer (Fig. 1b) created after $10 \mathrm{~h}$ is overgrown by a layer of iron oxides [16] even to 3-3.5 $\mu \mathrm{m}$ (Fig. 1d), causing also sintering of grains (Figs. 1b,c). Observed are also the changes caused by baking in internal structure of base grains, described in [16]. Visible is segregation of elements and local loss of $\mathrm{Mg}$ in form of brighter areas (Figs. 1b-d) and characteristic needle-shaped grains [16] similar to Widmanstätten structure, see (Figs. 1c,d).

\section{Evaluation of chromite-based moulding sands}

Both fresh $(0 \mathrm{~h})$ and baked (10 h and $24 \mathrm{~h})$ chromite base was used for manufacture of moulding sands. According to the recommendations for each of the applied hardening ways $\left(\mathrm{CO}_{2}\right.$ process, Floster $\mathrm{S}$, traditional drying, microwave heating), moulding mixtures were prepared in a laboratory ribbon mixer. The following amounts were dosed per 100 weight parts of chromite sand:

- $\mathrm{CO}_{2}$ process $\left(\mathrm{CO}_{2}\right): 0.5$ weight parts of R145 binder and stirring for $120 \mathrm{~s}$,

- Floster S (F24): 0.06 weight parts of ester hardener (Flodur 1) and stirring for $120 \mathrm{~s}$, next 0.5 weight parts of R145 binder and stirring for $120 \mathrm{~s}$,

- $\quad$ traditional drying (TD) or microwave heating (MH): 0.1 weight parts of water and stirring for $120 \mathrm{~s}$, next 0.5 weight parts of R145 binder and stirring for $120 \mathrm{~s}$.

It should be noted that, for comparative reasons, all the moulding sands were prepared with the same addition $(0.5 \%)$ of non-modified binder R145.

In the $\mathrm{CO}_{2}$ process, the moulding sands were hardened by blowing the shapes with unheated carbon dioxide for $30 \mathrm{~s}$ under $0.05 \mathrm{MPa}$. In the F24 process, formed shapes were put aside for 24 hours for complete hardening. At traditional drying, the shapes were dried for 30 minutes at $110^{\circ} \mathrm{C} \pm 0.1^{\circ} \mathrm{C}$ in a laboratory drier SL $53 \mathrm{TOP}+$. In the microwave process, the shapes were heated for $240 \mathrm{~s}$ in a laboratory microwave furnace under microwave power $1 \mathrm{~kW}$.

Results of tensile testing of the moulding mixtures prepared of fresh $(0 \mathrm{~h})$ and baked $(10 \mathrm{~h}$ and $24 \mathrm{~h})$ sand bases are shown in Fig. $2\left(R_{m}^{U}\right)$ and Fig. $3\left(R_{g}^{U}\right)$. The presented results are average values of minimum three measurements on the tester LRuE-2e made by Multiserw-Morek. Apparent density $\left(\rho_{0}\right)$ was 2.51 to $2.73 \mathrm{~g} / \mathrm{cm}^{3}$ for the moulding sands hardened in the $\mathrm{CO}_{2}$, TD and $\mathrm{MH}$ processes, and 2.65 to $2.82 \mathrm{~g} / \mathrm{cm}^{3}$ for those hardened in the $\mathrm{F} 24$ process.

The effects of baking show, first of all, differences between the moulding sands hardened in various ways. It is clearly demonstrated that microwave heating $(\mathrm{MH})$ and traditional drying (TD) are the most favourable of the suggested hardening methods.

With the same binder content, for fresh sand $(0 \mathrm{~h})$ obtained was 8-fold (TD) and 11-fold (MH) increase of $R_{m}^{U}$ and $R_{g}^{U}$ values in comparison to the $\mathrm{CO}_{2}$ process. For the F24 process, the $R_{g}^{U}$ value is nearly 3 times or 4 times smaller than the values for the 


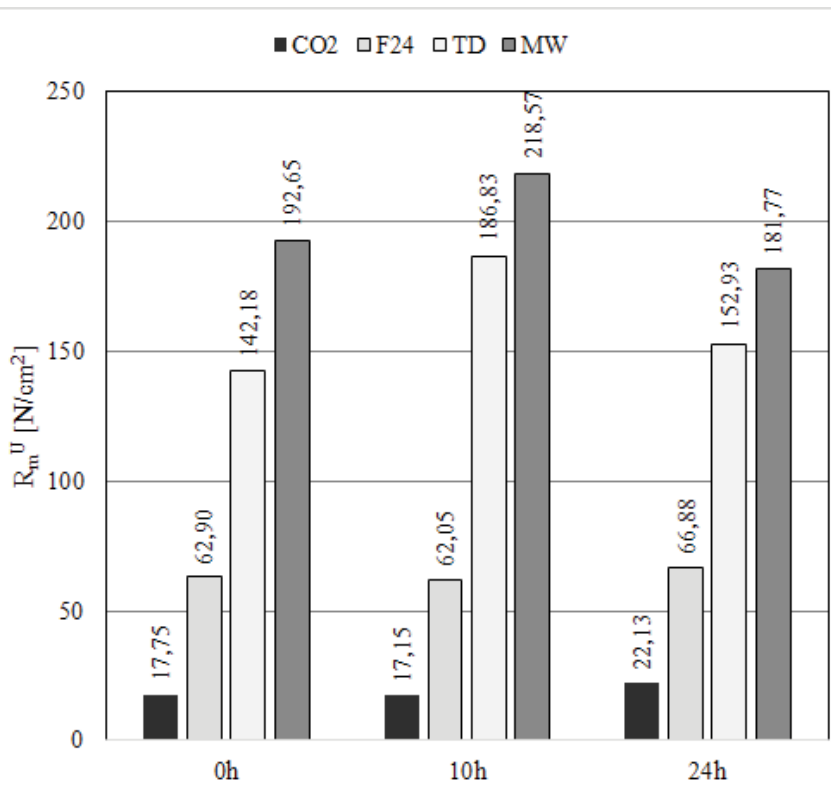

Fig. 2. Effect of baking chromite base and method of hardening on tensile strength of moulding sands containing sodium silicate

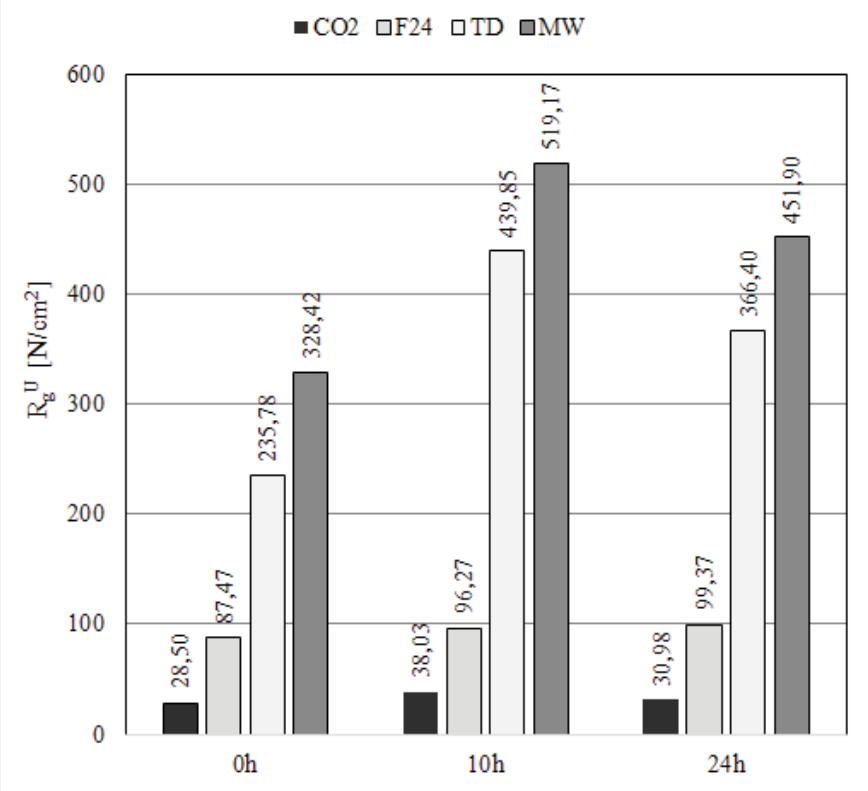

Fig. 3. Effect of baking chromite base and method of hardening on bending strength of moulding sands containing sodium silicate

TD and MH processes, respectively. Similarly, the $R_{m}^{U}$ value for the F24 process is 2 times or 3 times smaller than the values for the TD and $\mathrm{MH}$ processes, respectively.

Baking the chromite-base for $10 \mathrm{~h}$ resulted in increased strength of the moulding sands hardened by the physical methods MH and TD. The $R_{g}^{U}$ value for the MH process is by $190 \mathrm{~N} / \mathrm{cm}^{2}$ larger (Fig. 3) than that for the moulding sand prepared of fresh chromite sand. Similarly, the $R_{g}^{U}$ value for the TD process is as much as $204 \mathrm{~N} / \mathrm{cm}^{2}$ i.e. $87 \%$ larger than that for fresh $(0 \mathrm{~h})$ base. The $R_{m}^{U}$ value was also increased by baking for 10 hours, however this improvement is not as spectacular as in the case of $R_{g}^{U}$. Baking for 10 hours resulted in nearly 13-fold increase of $R_{m}^{U}$ and nearly 14-fold increase of $R_{g}^{U}$ in comparison to the $\mathrm{CO}_{2}$ process.

Further baking the base sand for 24 hours, and so the observed growth of the external rough layer composed mainly of iron oxides, did not result in any improvement of strength of the moulding mixtures hardened in all the four ways. The $R_{m}^{U}$ values in the TD and $\mathrm{MH}$ processes became equal to those obtained for the moulding mixtures based on fresh sand. After MH hardening, even a $6 \%$ decrease of $R_{m}^{U}$ was observed. The mechanical strength values decreased in spite of increased surface areas of grains as a result of 24-h baking. Tensile and bend tests of the moulding sand after 24 -h baking, hardened by microwaves, were repeated because some of the specimens broke during fitting in the LRuE-2e tester. The probable cause are local drops of strength [15] resulting from high temperature exceeding $220^{\circ} \mathrm{C}$ in microwave-heated specimens, see Fig. 4.

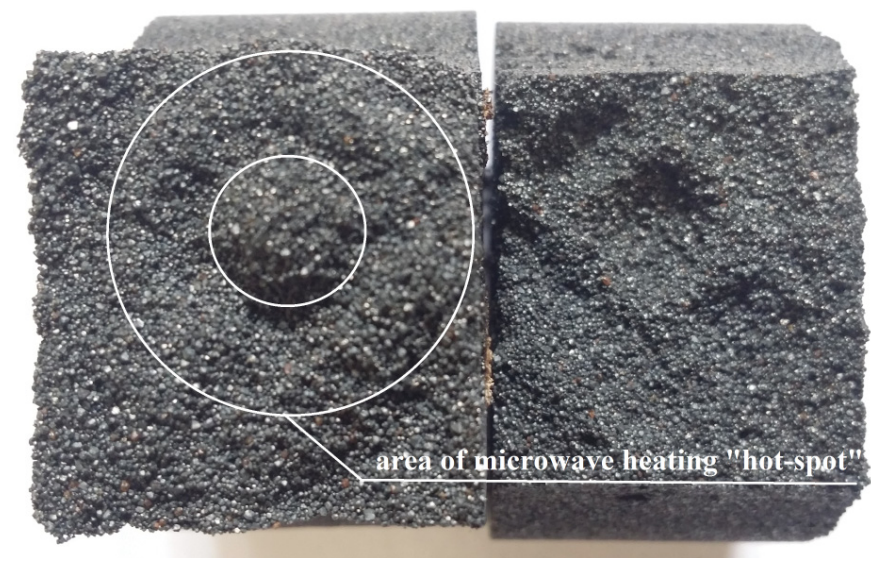

Fig. 4. Fracture surfaces of a dog-bone specimen ( $24 \mathrm{~h})$ in the place of thermal destruction caused by microwave heating

The phenomenon of local heating-up of the specimens and thus a change of their dielectric parameters can be affected by the changes occurring in the grains themselves, e.g. as a result of segregation of elements [18,19] during baking for $24 \mathrm{~h}$ at $950^{\circ} \mathrm{C}$. However, this is not the subject of this paper and would require additional analyses.

The strength values $R_{m}^{U}$ and $R_{g}^{U}$ of the moulding sands hardened in the $\mathrm{CO}_{2}$ or $\mathrm{F} 24$ process do not change depending on use of fresh $(0 \mathrm{~h})$ or baked (10 $\mathrm{h}$ and $24 \mathrm{~h})$ base sand.

\section{Effect of hardening method on structure of bonding bridges}

As was found in the case of moulding mixtures containing hydrated sodium silicate, hardened by $\mathrm{CO}_{2}$ or by liquid esters (Floster S), strength values $\left(R_{m}^{U}\right.$ and $\left.R_{g}^{U}\right)$ practically did not change in spite of baking base chromite sand. Results of mechanical testing are confirmed by observations of bonding bridges (Figs. 5-8) on fracture surfaces after tensile test by means of the scanning microscope Hitachi TM-3000. In the case of chemical hardening methods (Figs. 5,6) the least favourable blowing with 
$\mathrm{CO}_{2}$ gives for chromite-based moulding sands a similar result like for quartz-based sandmixes. Bonding bridges show numerous discontinuities and spallings, and their fracture in tensile test runs in the bridge material (cohesive destruction) revealing quite often complete shapes of bridge footings. Similar disadvantageous structures of the bridges are observed also for moulding sands hardened in the F24 process, see Fig. 6.
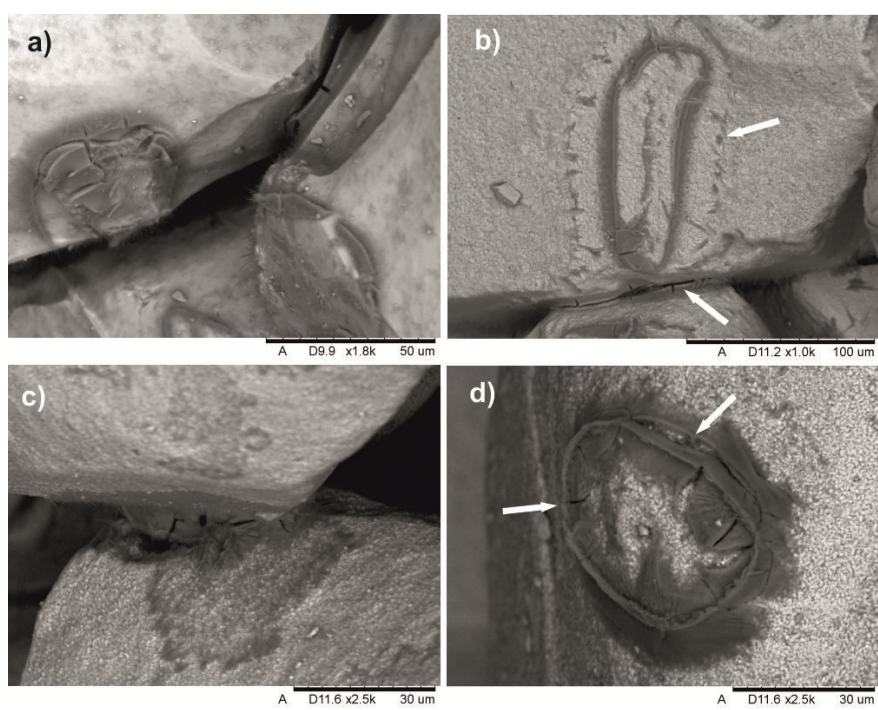

Fig. 5. Bonding bridges with numerous discontinuities in their footings arisen after hardening with $\mathrm{CO}_{2}$. Chromite base baked previously for: a) $0 \mathrm{~h}, \mathrm{~b}) 10 \mathrm{~h}, \mathrm{c})$ and d) $24 \mathrm{~h}$
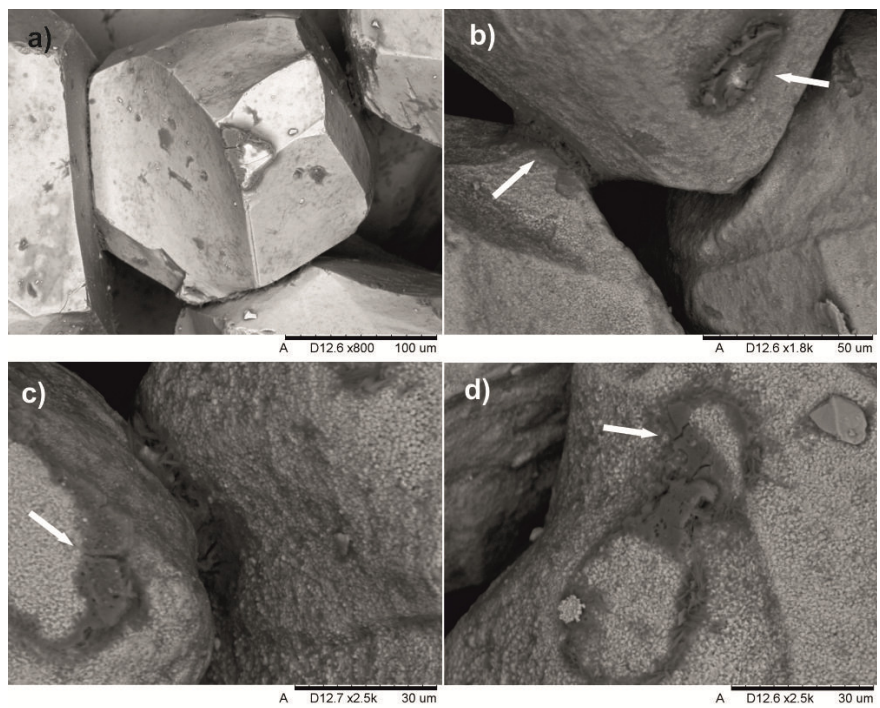

Fig. 6. Bonding bridges with numerous discontinuities in their footings arisen after hardening in the Floster S (F24) process. Chromite base baked previously for: a) $0 \mathrm{~h}$; b) $10 \mathrm{~h}$; c) and d) $24 \mathrm{~h}$

In the case of traditional drying (TD, Fig. 7) and microwave heating (MH, Fig. 8), observations of bonding bridges in fracture places of dog-bone specimens confirmed very good mechanical parameters of moulding sands. Structure of bonding bridges obtained after $\mathrm{CO}_{2}$ hardening on surfaces of fresh chromite sand grains is typical for physical hardening methods: they are free of defects and show ambiguous, i.e. cohesive-adhesive way of destruction. As a result of previous thermal preparation of sand base (baking for $10 \mathrm{~h}$ and $24 \mathrm{~h}$ ), numerous irregularities and cavities appeared on grain surfaces, which enlarged the surface area creating footings of bonding bridges. This phenomenon is conducive for mechanical adhesion [20] that supports creation of a durable layer with adhesive bonds in the adsorption zone on the interface of base-binder. Moreover, the applied preliminary wetting facilitated inflow of binder to its concentration places. As a result of traditional drying, strength of the R145 binder many times exceeds cohesion forces of the chromite base material, as shown in (Figs. 7c,d,f). Shapes of the observed fractures evidence a high force required for destroying bonds between chromite base grains, and at the same time, high hardness and brittleness of chromite.
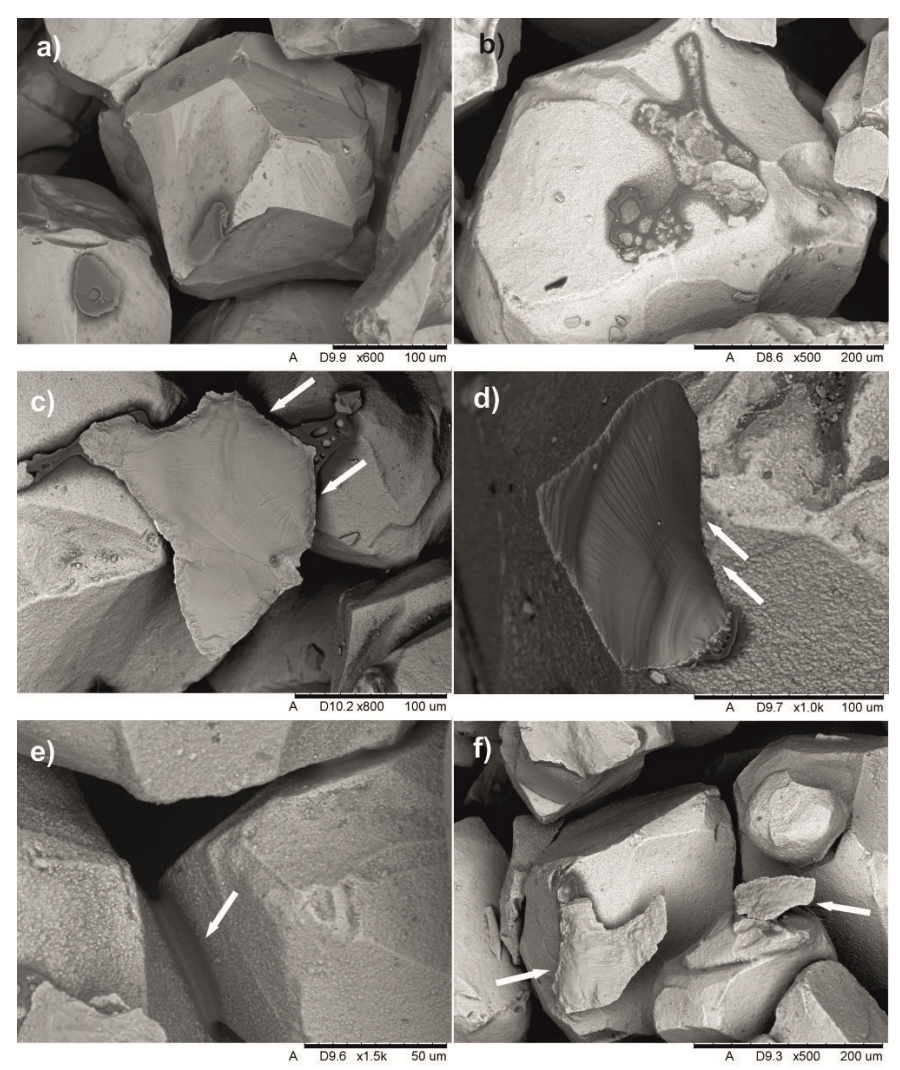

Fig. 7. Bonding bridges arisen after traditional drying (TD). Chromite base baked previously for: a) $0 \mathrm{~h}$; b), c) and d) $10 \mathrm{~h}$; e) and f) $24 \mathrm{~h}$. Arrows at: c), d), f) indicate brittle fractures after tensile test

Figure 8 shows bonding bridges created during microwave heating of chromite-based moulding sand. In the case of using fresh base (Fig. 8a), structure of bonding bridges hardened by microwave heating is similar to those hardened by traditional drying: smooth, arcwise with developed footings. In the moulding mixtures prepared of baked base sand (10 h and $24 \mathrm{~h}$ ), a significant change of structure of bonding bridges is observed. This consists in "sliming" the footings and appearing distinct thin walls strengthening the internal openwork structure of bonding bridges, see (Figs. 8b-d). Binder is clearly concentrated at the bridge footings, in the adsorptive zone, which permits their further spatial development (Fig. 8d) during microwave heating. 
This phenomenon can be a result of many factors conducive to inflow of the binder over the chromite grain surface developed by thermal treatment. This is certainly related to the accelerated process of microwave heating of moulding sand (base sand, water supporting microwave absorption and hydrated sodium silicate) [17]. In the case of bonding bridges created during microwave heating, destruction caused by the applied tensile load proceeded, first of all, in the material of sodium silicate film, and so in the cohesive way.
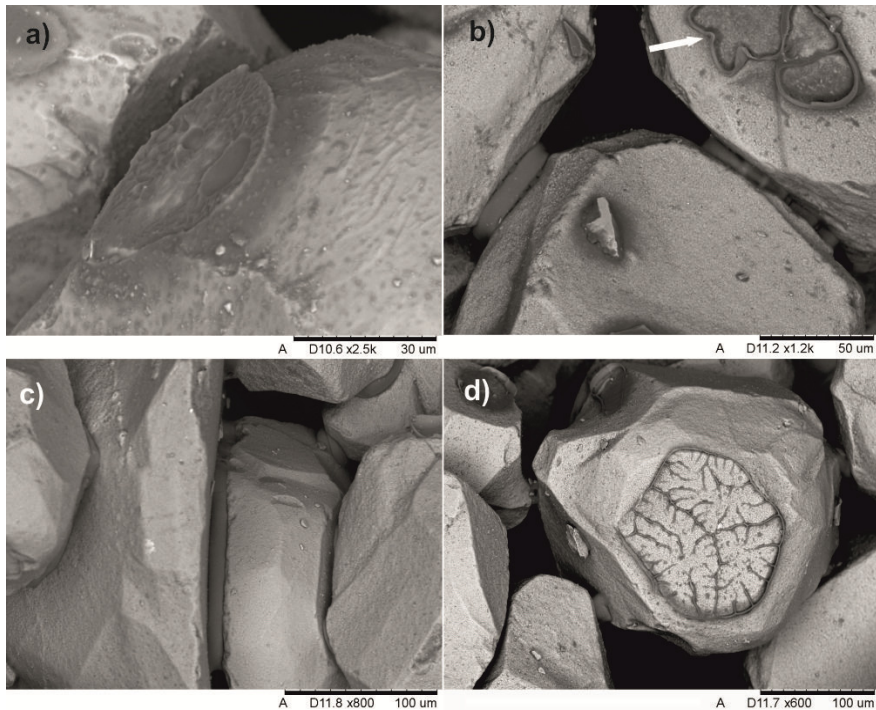

Fig. 8. Bonding bridges arisen after microwave heating (MH). Chromite base baked previously for: a) $0 \mathrm{~h}$; b) $10 \mathrm{~h}$; c) and d) $24 \mathrm{~h}$

\section{Conclusions}

Results of the research on the effect of thermal preparation of chromite base and selected hardening methods of moulding sands containing hydrated sodium silicate lead to the following conclusions:

- Quality of bonding bridges, and thus their structure, depend on the time of baking base sand and on the method of hardening sodium silicate (water-glass) binder.

- The most favourable, enabling a significant reduction of binder consumption, are physical hardening methods: microwave heating and traditional drying.

- With extending baking time, increases thickness of the rough layer composed mostly of iron oxides, conducive to creation of a durable layer in the adsorptive zone at the interface base-binder, but resulting in higher demand for the binder.

- In the case of chemically hardened moulding sands, dominating is cohesive nature of destruction of bonding bridges.

- In the case of moulding mixtures hardened by traditional drying, destruction of bonding bridges proceeds in the material of chromite base, which can result in increased part of fine fraction in the reclaim.

- After a specific time of baking base sand, hardening moulding sands by microwave heating allows reduction of the binder demand and the observed way of cohesive destruction of bonding bridges allows activation of thermally reacted sodium silicate.

\section{REFERENCES}

[1] J.L. Lewandowski, Materials for foundry moulds, 1997 Akapit, Kraków.

[2] E. Janicki, W. Sakwa, Moulding materials-properties and application, 1965 Wydawnictwo Naukowo-Techniczne, Warszawa.

[3] W. Sakwa, T. Wachelko, Materials for foundry moulds and cores, 1981 Śląsk, Katowice.

[4] H. Ważny, D. Substyk, Kwartalnik Geologiczny 19 (4), 805-812 (1975)

[5] Polish Norm PN-91/H-11007. Chromite sand.

[6] J. Jakubski, St.M. Dobosz, Archives Of Foundry 6 (18), 453-458 (2006).

[7] S. Bengulur, H.R. Darwada, K.R. Gurram, P.R. Vundavilli, Recent Advances in Robotics, Aeronautical and Mechanical Engineering, ISBN: 978-1-61804-185-2

[8] A. Modrzyński, Solidification of Metals and Alloys 2 (43), 375382 (2000).

[9] M. Hajkowski, Archives of Foundry 4 (14), 154-162 (2004).

[10] P. Jelínek, T. Elbel, Archives of Foundry Engineering 10 (4), 77-82 (2010).

[11] St.M. Dobosz, P. Jelinek; K. Major-Gabrys, China Foundry 8 (4), 438-446 (2011).

[12] A. Bobrowski, M. Holtzer, Arch. of Foundry Eng. 10 (spec. iss. 2), 19-22 (2010).

[13] Z. Ignaszak, J-B. Prunier, Archives of Foundry Engineering 16 (3), 162-166 (2016).

[14] R. Dańko, M. Holtzer, J. Dańko, Arch. Metall. Mater. 60 (1), 313-318 (2015).

[15] M. Stachowicz, K. Granat, A. Małachowska, Arch. of Foundry Eng. 14 (spec. iss. 2), 83-88 (2014).

[16] M. Stachowicz, M. Kamiński, K. Granat, Ł. Pałyga, Arch. of Foundry Eng. 16 (4), 147-152 (2016).

[17] M. Stachowicz, J. Mażulis, K. Granat, A. Janus, Metalurgija 53 (3), 317-319 (2014).

[18] K. Wiśniewska, J. Szczerba, Materiały Ceramiczne /Ceramic Materials/ 66 (3), 341-344 (2014)

[19] Y. Murakami, A. Sawata, Y. Tsuru, J. Mater. Sci. 34, 951-955 (1999).

[20] A. Baliński, About the structure of the hydrated sodium silicate as a molding sands binder, (2009) Foundry Research Institute, Kraków. 